\title{
An atypical presentation of acute coronary syndrome
}

\author{
Amir Solomonica ${ }^{1}$, Shahar Lavi ${ }^{1}$, Tawfiq Choudhury ${ }^{1}$, Rodrigo Bagur ${ }^{1,2}$ \\ ${ }^{1}$ London Health Sciences Centre, London, Ontario, Canada; ${ }^{2}$ Keele Cardiovascular Research Group, Centre for Prognosis Research, Institute of \\ Primary Care and Health Sciences, University of Keele, Stoke-on-Trent, UK \\ Correspondence to: Rodrigo Bagur, MD, PhD, FAHA. Interventional Cardiologist, London Health Sciences Centre, University Hospital, 339 \\ Windermere Road, N6A 5A5, London, Ontario, Canada. Email: rodrigobagur@yahoo.com.
}

Submitted Mar 16, 2018. Accepted for publication Jun 06, 2018.

doi: $10.21037 /$ jtd.2018.07.55

View this article at: http://dx.doi.org/10.21037/jtd.2018.07.55

\section{Case presentation}

A 53 -year-old woman, with a body mass index of $25.6 \mathrm{~kg} / \mathrm{m}^{2}$, and a past medical history consisting of type 2 diabetes mellitus diagnosed 10 years earlier, hypertension, hyperlipidemia and remote smoking presented to the emergency department complaining of chest heaviness, shortness of breath and general myalgia. Her heart rate was 114 beats per minute, blood pressure was 190/100 $\mathrm{mmHg}$, and she was quite anxious. The initial electrocardiogram (ECG) (Figure 1) showed ST-elevation in AVR and diffuse ST depression in anterolateral and inferior leads. First Troponin-T Level measurement was $39 \mathrm{ng} / \mathrm{L}$ and the next one elevated to $67 \mathrm{ng} / \mathrm{L}$ (normal $\leq 14 \mathrm{ng} / \mathrm{L}$ ). The initial diagnosis was acute myocardial infarction and therefore, she was transferred to our medical center for urgent coronary angiogram. Transradial coronary angiography revealed non-obstructive coronary artery disease and left ventriculography showed preserved ejection fraction with antero-basal hypokinesis.

Her systolic blood pressure fluctuated from highs of $190 \mathrm{mmHg}$ to lows of $120 \mathrm{mmHg}$. It was decided to perform a computed tomography (CT) thorax. During preparation for this, she received intravenous (IV) metoprolol to slowdown her heart rate, and subsequently became hypertensive with a blood pressure as high as 220/110 $\mathrm{mmHg}$. The CT did not reveal any other cardiovascular pathologies but rather a large and partially visualized heterogeneous right adrenal mass as an incidental finding. An abdominal CT which was later done confirmed a right adrenal gland mass measuring $6.6 \mathrm{~cm} \times 4.6 \mathrm{~cm}$ in cross section and $7.4 \mathrm{~cm}$ in cranial-caudal dimension with marked vascularity. No left adrenal gland mass was observed. In light of the patient's presentation, the leading differential diagnosis was changed to pheochromocytoma. Initial medical management with Doxazosin was started. Since the patient was still tachycardic, Diltiazem was prescribed and later on, she was also started on beta blockers. The 24-hour urine levels of catecholamines and fractionated metanephrines were very high. On SPECT/CT, there was a ${ }^{123}$ I meta-iodobenzyl-guanidine (MIBG) avid right adrenal mass (Figure 2). Two weeks after the initial diagnosis, the patient underwent successful laparoscopic right adrenal resection. Pathology examination revealed neoplastic cells with prominent eosinophilic granular cytoplasm and round salt-and-pepper nuclei. Immunohistochemistry showed that the neoplastic cells were positive for synaptophysin and chromogranin. Hence, the morphological and immunohistochemical features confirmed the diagnosis of pheochromocytoma. On later follow-up visits, her blood pressure was wellcontrolled and eventually she was taken off both alpha and beta blockers. Subsequent urine levels of catecholamines and fractionated metanephrines remained low and her left ventricular function on echocardiogram returned to normal as did her ECG (Figure 3). Importantly, the surgical treatment of the pheochromocytoma had a beneficial impact on her diabetes control.

\section{Discussion}

Pheochromocytomas are catecholamine-producing neuroendocrine tumors arising in $85 \%$ of the cases from chromaffin cells of the adrenal medulla. The remaining $15 \%$ of the cases which arise from extraadrenal paraganglia are referred to as paragangliomas (1). Pheochromocytomas may be sporadic or hereditary such as in multiple endocrine neoplasia type 2, von Hippel- 


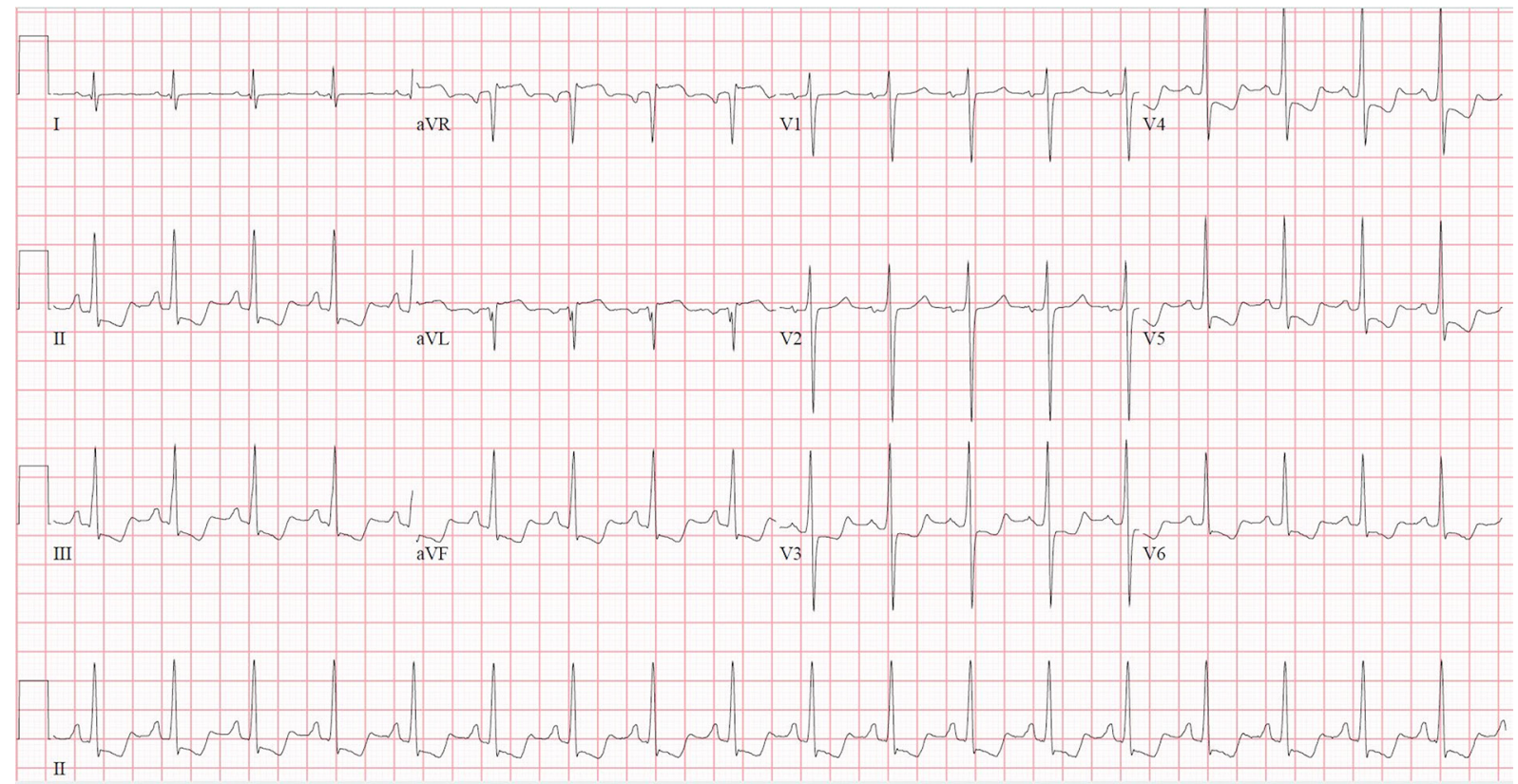

Figure 1 Initial 12-lead electrocardiogram showing sinus tachycardia, diffuse ST-segment depression and ST-segment elevation in AVR.
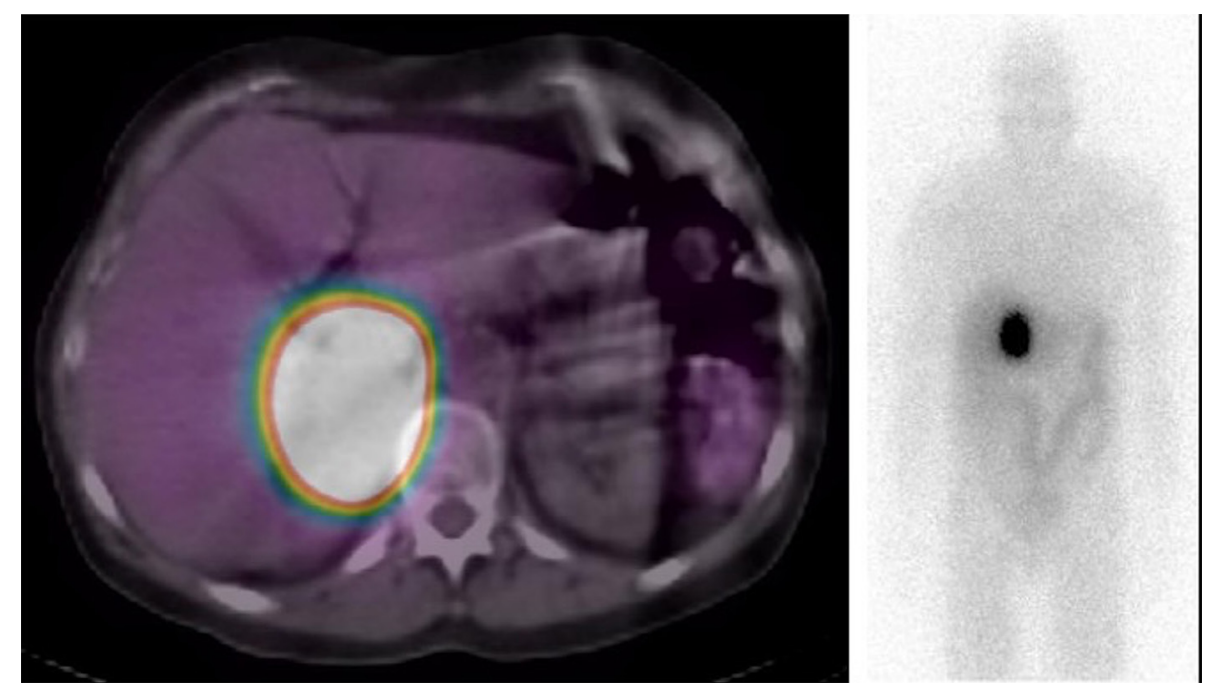

Figure 2 SPECT/CT image showing a $6.6 \mathrm{~cm} \times 4.6 \mathrm{~cm}$ right adrenal mass and ${ }^{123} \mathrm{I}$ meta-iodo-benzyl-guanidine avid.

Lindau syndrome and neurofibromatosis type 1 (1). In general, pheochromocytomas are rarely diagnosed, with a prevalence of $0.1-0.6 \%$ amongst patients being screened for hypertension (1)

The classic signs and symptoms related to pheochromocytomas are hypertension, headache, tachycardia, palpitations and pallor. These are often paroxysmal thus making the diagnosis even harder. Less often, the initial manifestation is cardiac in nature such as heart failure, myocardial infarction and arrhythmia (2). Since the presenting signs and symptoms are variable and non-specific, this often leads to a very prolonged delay in diagnosis. In patients presenting with cardiac manifestations the lack of obstructive coronary artery disease may indicate a direct toxic effect 


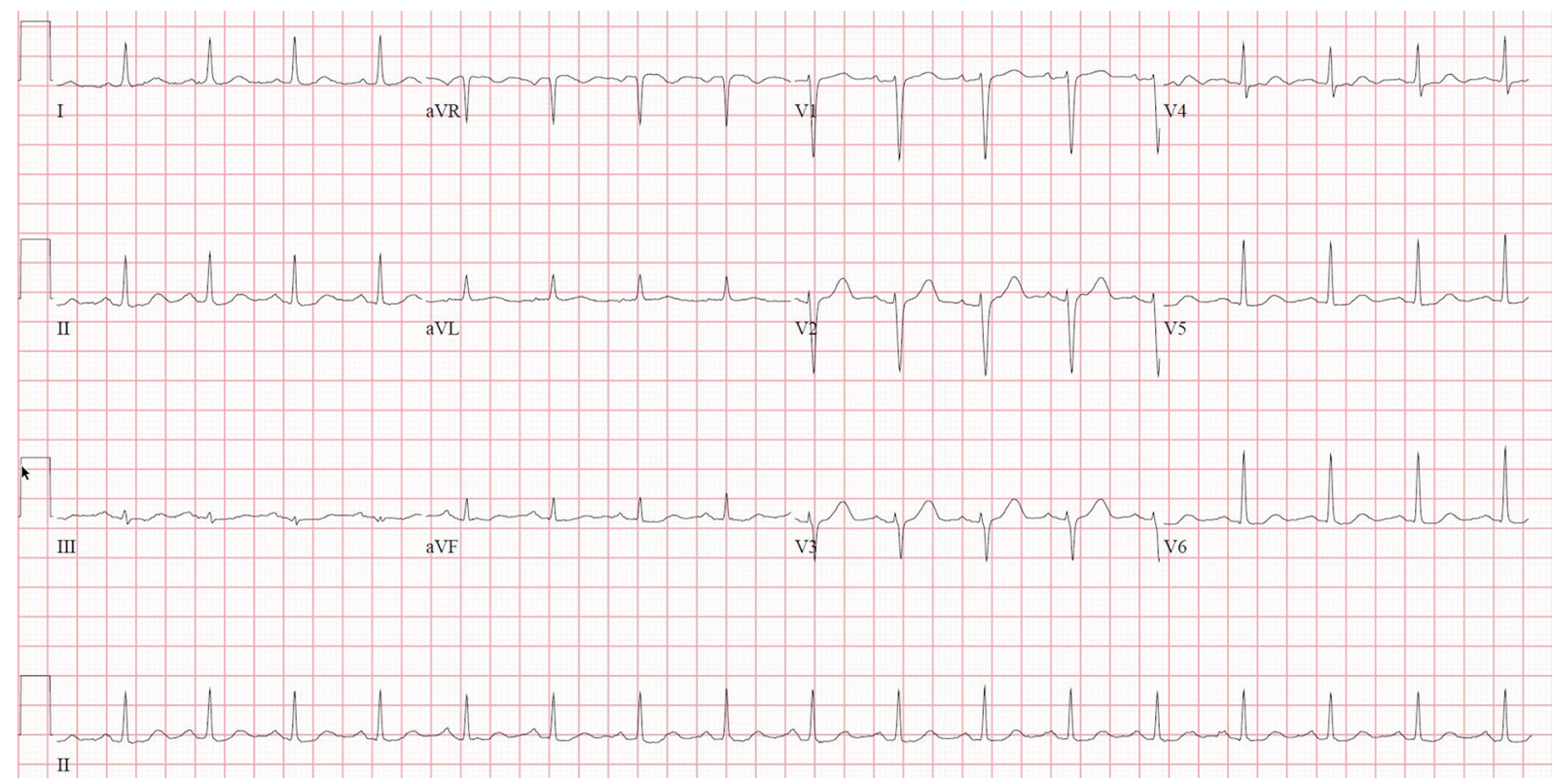

Figure 3 12-lead ECG showing in follow-up visit showing resolution of ST-segment abnormalities. ECG, electrocardiogram.

of catecholamines on cardiomyocytes or an indirect effect inducing ischemia by increasing the myocardium's oxygen demand and afterload (3).

Because the presentation is often non-specific, prior publications presented patients that had non-specific ECG changes (if any) or no rise in Troponin. Moreover, in some of these cases previous diagnoses were an important "clue" for diagnosing pheochromocytoma such as status post adrenalectomy, status post thyroidectomy due to thyroid cancer, etc., abdominal pain, fever and/or significant tachycardia (4-7). The patient presented here had an initial ECG with significant changes that were highly suggestive of acute coronary syndrome and the Troponin levels rose accordingly. She had no prior relevant medical history that may have associated her with pheochromocytoma. A high prevalence of pheochromocytoma had been shown in young diabetic patients with low body mass index and hypertension, hence, unlike our patient. On the other hand, previous reports showed that patient's diabetes did not improve after surgery and had actually worsened the levels of Hemoglobin A1c (8).

In conclusion, the presentation of pheochromocytomas as acute myocardial infarction is rare and therefore, important for clinicians to recognize this differential diagnosis. When there is clinical suspicion that pheochromocytoma is the cause, especially when primary investigations did not lead to a definite conclusion, initial work up should include biochemical testing for urinary metanephrines and, if positive, further localization by magnetic resonance, CT or nuclear scan is warranted, since a timely treatment often leads to complete recovery.

\section{Acknowledgements}

None.

\section{Footnote}

Conflicts of Interest: The authors have no conflicts of interest to declare.

Informed Consent: We were unable to obtain informed consent; however, we believe that in the present format, we still protect the patient's privacy.

\section{References}

1. Lenders JW, Eisenhofer G, Mannelli M, et al. Phaeochromocytoma. Lancet 2005;366:665-75.

2. Yu R, Nissen NN, Bannykh SI. Cardiac complications as initial manifestation of pheochromocytoma: frequency, outcome, and predictors. Endocr Pract 2012;18:483-92. 
3. Prejbisz A, Lenders JW, Eisenhofer G, et al. Cardiovascular manifestations of phaeochromocytoma. J Hypertens 2011;29:2049-60.

4. Vilcant V. Pheochromocytoma-Induced Cardiomyopathy Mimicking Acute Coronary Syndrome. J Am Osteopath Assoc 2017;117:537-40.

5. Martin JF, Martin LN, Yugar-Toledo JC, et al. Coronary emergency and diabetes as manifestations of pheochromocytoma. Int J Cardiol 2010;139:e39-41.

6. Yang TH, Tsai WC. Recurrence and metastasis of

Cite this article as: Solomonica A, Lavi S, Choudhury T, Bagur R. An atypical presentation of acute coronary syndrome. J Thorac Dis 2018;10(8):E616-E619. doi: 10.21037/ jtd.2018.07.55 pheochromocytoma mimic acute ST-segment elevation myocardial infarction: a case report. Am J Emerg Med 2015;33:311.e3-5.

7. Horton WB, Frey LM, Hawkins UA, et al. Pheochromocytoma presenting as acute non-ST elevation myocardial infarction following elective hysterectomy. J Miss State Med Assoc 2015;56:4-6.

8. La Batide-Alanore A, Chatellier G, Plouin PF. Diabetes as a marker of pheochromocytoma in hypertensive patients. J Hypertens 2003;21:1703-7. 